\title{
ENTRE POETAS ESTAMOS: NOCES, DE CAMUS Y CÁNTICO, DE GUILLÉN
}

\author{
Among poets we are: Noces (Camus) and Cántico (Guillén)
}

Alí Viquez Jiménez

\begin{abstract}
RESUMEN
Este artículo desarrolla una comparación entre los textos Noces, de Albert Camus, y Cántico, de Jorge Guillén. Se propone profundizar en la elaboración estética y filosófica que ambos autores realizan al abordar el estado de la dicha humana y la celebración de esta por medio de la palabra. Al contrastar los textos, llega a conclusiones sobre la valoración del presente como punto común y establece los diferentes matices con que se efectúa tal valoración.

Palabras clave: Literatura francesa, literatura española, literatura comparada, literatura europea contemporánea, poesía española.

ABSTRACT

This essay develops a comparison between the texts "Noces" (Albert Camus) and "Cántico" (Jorge Guillén). Its objective is to deepen the aesthetic and $\mathrm{ph}^{1}$ ilosophical approach that both authors make about the state of human happiness and its celebration by means of the poetical word. By contrasting the texts, the paper reaches conclusions about the assessment of the present, that has points in common in both writers, and establishes the differences with which the assessments are made.
\end{abstract}

Key Words: French literature, Spanish literature, Comparative literature, Contemporary European literature, Spanish poetry.

\section{Introducción}

En las páginas que siguen me propongo comparar dos textos literarios: Cántico, del poeta español Jorge Guillén, y Noces, del francés Albert Camus. Creo que a nadie se le había ocurrido efectuar esto, quizá porque dichos escritores parecen ser muy disímiles. Mientras Guillén es algo así como un perfecto ejemplo de quietud, armonía y equilibrio que se extienden de manera parsimoniosa durante una extensa carrera poética, Camus se suele asociar con la violencia de personajes como Calígula, los excesos pasivo-agresivos de ese extranjero llamado Meursault, la persistente desesperación que corroe el mundo narrativo de La peste. Eso sin mencionar los contrastes biográficos entre Guillén y Camus; el primero, retirado del mundanal ruido, el constante "poeta-profesor" (término no exento de

${ }^{1}$ Universidad de Costa Rica. Profesor catedrático de la Escuela de Filología, Lingüística y Literatura. Costa Rica. Correo electrónico: ali.viquez@ucr.ac.cr

Recepción: 07/03/2018. Aceptación: 07/06/2018. 
sorna que pergeñó Juan Ramón Jiménez) que se prodigó largo tiempo en pacíficas cátedras sobre todo estadounidenses, sin levantar la voz por encima de los límites de los campus universitarios; el segundo, el intelectual combativo, siempre al tanto de la vida política francesa y mundial, protagonista en el teatro y en la tribuna periodística, partícipe de la polémica en su relación con otros intelectuales igualmente activos, como Sartre, que lo malquiso con ardor digno de mejor causa, y muerto prematuramente, pero ya habiendo recibido un reconocimiento tan alto como el premio Nobel de Literatura. Los separaban solo veinte años (Guillén nació en 1893; Camus, en 1913) y provenían de países vecinos (además, Camus, nacido y criado en la Argelia francesa, tenía ascendencia española); no obstante, dan la apariencia de haber vivido en mundos muy distintos.

Al toparme con Noces, llamó mi atención la intensidad con la que el jovencísimo Camus (no ha cumplido aún los veinticinco cuando escribe este texto) defiende el disfrute de la vida. ${ }^{2}$ De ahí a relacionarlo con esa rara avis de la poesía española que es Guillén, uno de esos escasos celebrantes literarios de la felicidad, no había más que un paso. De manera que esta es la motivación inicial, y también me remite al propósito: frente a una literatura como la contemporánea (acaso esta sea una precisión innecesaria, y pueda hablarse de la de todos los tiempos), tan agobiada por desdichas, pretendo comparar dos textos que dan cuenta de sendos estados de felicidad. No me mueve solo la curiosidad, también la envidia (de la buena): quisiera saber, para mi provecho personal, por qué estos textos han logrado abrirle un espacio a la plenitud que no me parece nada frecuente en otras partes, ni del mundo ni del arte. Operar por la vía de una comparación me resulta más eficaz que simplemente estudiar cada texto por separado: en el contraste se halla un camino hacia la profundización que la literatura ha sabido proponer desde hace tiempo. Cuando don Quijote y Sancho conversan, los conocemos mejor por causa de sus diferencias; cuando Aliosha e Iván Karamázov discuten, ahondamos en sus posturas porque el contraste que escenifican produce una luz más intensa. La comparación, pues, me la planteo como una estrategia cognoscitiva.

Indagar en la felicidad descrita en dos textos literarios es un propósito que debe precisarse, no sea que uno caiga en el despropósito. En primer lugar, eludamos desde el

\footnotetext{
${ }^{2}$ Camus fue un escritor precoz: dejó escritos incluso anteriores a Noces. Véase Viggiani (1960).
} 
principio el error de creer que los textos reproducen el estado de ánimo real de sus autores. Sobre este, no se puede opinar por lo que un texto plantee: la felicidad o la desdicha personales no tienen por qué producir hermanos gemelos en la literatura. Un texto está sin duda atravesado por la sensibilidad de quien lo escribe, pero no dictado por el estado de ánimo de este. Bien se puede escribir para escapar de las circunstancias vitales concretas, o para desear otras en lugar de las que se tienen. Expresarse por medio de la literatura implica sacar la presión de dentro de sí hacia el exterior, pero en esta salida la transformación de lo que hay dentro es imprescindible porque el arte literario no se hace con la agitación interior, sino con las palabras del poeta. El propio Camus puntualiza: "Les œuvres d'un homme retracent souvent l'histoire de ses nostalgies ou de ses tentations, presque jamais sa propre histoire, surtout lorsqu'elles prétendent à être autobiographiques" (Camus citado por Onfray, 2012, p. 18). ${ }^{3}$

En segundo lugar, eludamos el desdén que producen los libros que plantean la posibilidad de la plenitud, si se les confunde con manuales de autoayuda. No hay nada de recetario en los textos que quiero estudiar; no hay nada especialmente sencillo en lo que proponen. La felicidad descrita no se basa en la simplificación de la mirada sobre el mundo. Este sigue siendo igualmente complejo cuando se le describe como un espacio apto para la plenitud. Dejemos aquí de considerar que la “depresión” es la única vía hacia la "profundidad". No se debe pretender que la dicha es un espacio uniforme. También en la felicidad descrita en estos textos literarios, hay sitio para los matices, las distinciones, las precisiones.

\section{Noces}

Esta colección de cuatro textos se escribió entre 1936 y $1937 .{ }^{4}$ El título proviene del primero, "Noces à Tipasa". Tipasa es una antiquísima ciudad argelina, fundada por los

\footnotetext{
${ }^{3}$ Irónica o apenas curiosamente, Michel Onfray, de cuyo libro extraigo esta cita, no le cree a Camus. Yo sí. A Onfray no le conviene creerle, puesto que está escribiendo un ensayo llamado L'ordre libertaire. La vie philosophique d'Albert Camus, el cual, si bien es muy interesante y valioso, quiere comprobar que Camus vivió tal cual lo predicó en sus libros. Esa comprobación requeriría de un detective más que de un filósofo como Onfray.

${ }^{4}$ En la crítica me he encontrado con su clasificación sobre todo como ensayos, pero en mi opinión se encuentran a medio camino entre la narración y el ensayo. Emily Tall (1980), por su parte, los considera "ensayos líricos"; digamos que el género al cual pertenecen no es lo más claro de estos textos. Ni lo más importante.
} 
fenicios, que en 1982 la UNESCO habría de declarar Patrimonio de la Humanidad, a causa de las ruinas romanas que allí se conservan. Pero el texto camusiano no es una reflexión sobre la historia o el pasado, sino una inspirada toma de contacto personal con el sitio. No busca presentar un razonamiento de cualquier tipo, sino dar cuenta de una inmersión en esa naturaleza que se adueña del entorno. Esta es una crónica pequeña (por su extensión, que no pasa de seis o siete páginas, y por la duración de la vivencia narrada, apenas un día) de una visita a un pueblo que se pliega ante las fuerzas de la naturaleza subyugante, sin que medie la violencia, sino más bien un esplendor y una conquista muy sensuales. El pueblo, fundado por los fenicios y que el emperador Claudio llenó de gloria, se deja moldear dulcemente por su relación con el sol, con el mar, con la vegetación y con el aire.

Un día basta al narrador visitante para sentirse parte de la dichosa vivencia de "recuperación" que se ejecuta en Tipasa. Las antiguas glorias arquitectónicas, hoy en ruinas, y el modesto pueblo actual, se rinden con placidez a la magnificencia de la naturaleza. Esta se manifiesta como una tendencia envolvente, pero con un ritmo amigable en el que no hay amenaza, sino una gentil acogida. Se da un dulce regreso al origen: "Dans ce mariage des ruines et du printemps, les ruines sont redevenues pierres, et perdant le poli imposé par l'homme, sont rentrées dans la nature" (Camus, 1959, p. 14). Siguiendo el ejemplo del entorno, no tarda el visitante en rendir su cuerpo también a los placeres sensuales del sol y el agua, el color y la flora. De todo ello se sigue no tanto un planteamiento filosófico (lo cual implicaría un razonamiento más riguroso que el aquí presente) cuanto una consecuencia vital: en el momento actual, el narrador comprueba que es posible ser feliz entregándose sin más a los deleites de un encuentro con ese mundo natural acogedor y próspero. La dicha ocurre al no oponerle resistencia a la experiencia del cuerpo, por la sabiduría al dejarse poseer por cuanto nos rodea. La frase que, en mi opinión, debe rescatarse como máxima filosófica es la siguiente: "Il n'y a pas de honte à être heureux. Mais aujourd'hui l'imbécile est roi, et j'appelle imbécile celui qui a peur de jouir" (p. 18). En ella se centra la crítica que, sin proponerse abiertamente desde el principio, el texto termina por ejecutar, fruto del espíritu combativo que aún en los momentos de mayor placidez acompañó a Camus, y es hacia quienes no son capaces de vivir en la inmediatez de los sentidos, en la plenitud del cuerpo, en el mundo que no se cansa de estar cerca de nosotros, y van a buscar a otra parte una realidad que los está apelando rotundamente aquí, 
rotundamente ahora. Son esos torpes los reyes que, pudiendo contraer las nupcias con la naturaleza, rehúsan lo que el cuerpo quiere. ${ }^{5}$

Un par de aclaraciones antes de seguir me parecen muy necesarias. Yo he mencionado la naturaleza, pero ello responde a una forma de sintetizar lo que el texto propone. Este no se inicia con generalizaciones: Camus habla en concreto del ajenjo, de las flores silvestres, del sol envolvente, de la tibieza del mar, de pinos y cipreses, de la brisa, de la sal, de las cigarras, del romero, del perfume embriagante: si llega a referirse a la naturaleza es después de concretar su existencia en ejemplos numerosos y nada abstractos. No se trata tanto de un concepto como de una experiencia particular, bella y cuidadosamente descrita. Además, Camus no separa tajantemente lo natural de lo cultural: en el centro mismo de sus vivencias corporales placenteras, está la huella de la construcción humana, integrada al mismo placer: no en balde (he transcrito ya la cita), Camus señala que los esponsales que celebra se dan también entre las ruinas y la primavera.

En el siguiente texto, "Le vent de Djémila", Camus desarrolla lo que en rigor ha comenzado a plantear en relación con Tipasa, pero ahora le da énfasis. Djémila es un yacimiento arqueológico; tras un pasado de glorias, la ciudad romana construida en terreno montañoso ha muerto en el siglo VI. En la urbe abandonada, que no lleva a ninguna parte, divorciada de la aldea próxima, Camus profundiza en la idea del abandono de cualquier trascendencia. En Tipasa ahondó en la dicha inmediata de una vida entregada a la naturaleza y en Djémila también se refiere a ello, pero en esta última insiste en el carácter presente de la vida y en la inutilidad de esperar ningún tipo de trascendencia de esta. El gozo de estar vivo es ahora y nunca más. La futilidad de las mitologías pasadas y actuales se torna evidente. Los dioses romanos o cristianos son solo formas de despreciar lo que hay de más importante para los seres humanos: sus experiencias sensoriales presentes. La reflexión ante la muerte se impone porque quien ve con perspicacia cómo se extinguieron las vanidades romanas inevitablemente sabe que las suyas también se extinguirán. El viento que golpea el rostro de quien visita Djémila le trae la evidencia de que no existe sino el hoy

${ }^{5}$ Michel Onfray los identifica con los enemigos de Nietszche: "Critique de la culpabilité judéo-chrétienne, critique du sentiment de peché, critique du poids de la faute, critique de la mésusage du corps, critique de l'invitation à réfuser tous les plaisirs du corps" (2012, p. 142). En la misma línea de lectura nietzscheana, aunque menos beligerante, puede consultarse a Massé (2015). Aunque no ha faltado, según entiendo, quien vea el budismo como la fuente de inspiración de Noces (véase la reseña de un libro, que desafortunadamente no pude conseguir, en Montgomery [2006]). Yo creo que Camus, por supuesto, tiene puntos de partida, pero desarrolla siempre un pensamiento original. 
para el ser humano. Sigue siendo la aventura del cuerpo lo que aquí se narra, pero ahora la piel se reseca, trabajada por los elementos, y el cuerpo entiende su carácter transitorio.

No hay afán de negar la amargura que produce el saberse mortal. El corazón se oprime al visualizarse tan próximo el ser humano a la ciudad en ruinas, tan coincidentes los destinos de ambos. Pero la desesperación ante la muerte puede conducir a la belleza. Camus encuentra en la lucidez un camino hacia la vivencia artística que el engaño de pretenderse trascendente no proporciona. Renuncia a todos los "después" con que se mienten los débiles, para abrazar el "ahora" que abre la puerta hacia el arte. Y no es que este consiga trascender, pero permite visualizar con dignidad y hermosura algo que, como la muerte, se califica aquí de "sucia aventura".

Ahora bien, el arte no es la panacea. Es simplemente una forma de vivir una belleza que es triste, o una tristeza que es bella. Escribir es extender sobre el papel el goce del cuerpo que se sabe mortal, y que vive esa contradicción de placer inmediato y temor ante el mañana que devorará ese placer. Este lo dan también las palabras: un goce que pocos escritores negarían. Una forma entre muchas: lejos está Camus de pretender que en la escritura se encuentra el monopolio de la experiencia estética. Lo único que Camus establece como necesario para el goce es renunciar al "después" y vivir el "ahora".

Esta idea de un pueblo que vive en el ahora la desarrolla en el tercer texto, "L'été en Argel", en el cual se desvía del camino al que lo llevaban sus reflexiones previas acerca del arte. Sin pretender ningún tipo de habilidad artística especial en el pueblo argelino que describe, le atribuye, sí, un apego rotundo al presente. En el país en el que la naturaleza lo da todo ahora, el ser humano lo recibe todo, sin aspirar a más. El sol de Argelia, el sol del verano sin resquicios, convierte al pueblo en un ser uniformemente entregado a su cuerpo, e incluso agotado con rapidez por esa entrega. En otras partes (como París) la vida se puede poner entre paréntesis ilusoriamente, en Argelia nadie vive esa mentira. La belleza a la que se tiene acceso, como el sol inclemente, se bebe deprisa y se exprime pronto: la juventud allí se agota plenamente (valga el oxímoron), sin ambages, en lo que podría parecer un atracón de placeres casi rudimentarios, pero es más exacto llamar elementales: el erotismo, la inmersión en la naturaleza, e incluso el abandono que implica la pobreza, pues esta fortalece el lazo con lo más básico de la existencia: el hambre, la necesidad de procurarse 
un techo, el saberse unido a quienes también son pueblo. ${ }^{6}$ Después queda el ser humano frente a su acabamiento y su realización: quiere Camus decir que la vida se termina pronto bajo el verano intenso de Argelia.

Camus, en este texto sobre el sol africano, se separa del arte para dejarse llevar únicamente por la vida en su forma más básica, tal como la percibe en Argelia. Pero su viaje sigue; vale decir que la escritura continúa. El cuarto texto abandona el entorno africano para lanzarse sobre la Europa más estilizada: Italia y, sobre todo, Florencia. Nadie puede irse de la cultura, por mucho que la conciba directamente derivada de la naturaleza, como en el caso de Camus con la cultura de Argelia, lo cual -admitamos- no deja de arrastrarlo a cometer una generalización apresurada: Camus desarrolla una visión de los argelinos excesivamente monótona; los mira a todos como iguales, seres elementales (aunque este término debe pensarse en un sentido positivo: ligados a los elementos naturales) entre los cuales no hay mayores diferencias. Por mucho que Camus creciera en Argelia, la suya no deja de ser un poco la visión de un extranjero (algo de Meursault se le manifestaba; algo de francés por sobre lo africano).

El cuarto texto comienza planteando la creación de la cultura como lo contrario de la vida: "Vivre, bien sûr, c'est un peu le contraire d'exprimer" (p. 58). Pero pronto nos damos cuenta de que Camus sabe que la existencia es imposible sin expresarse, al menos para quien, como él, no tiene más remedio que hacerlo para buscar el sentido de la vida y de la muerte. Camus deberá admitir que él no es tan elemental como pretende que lo es ese pueblo argelino descrito en "L'été en Argel”.

Leerá Camus el arte italiano como una comprobación de su propia verdad: según él, la pintura de los maestros toscanos ejecuta una exaltación del presente del cuerpo (no del espíritu) y una protesta por la ausencia de un dios que salve a los seres humanos de la muerte. Para Camus, estos pintores se ocupan de una verdad bien diferente de la que se escucha en las iglesias, y es aquí donde se alcanza la poesía más alta:

Par vérité je veux seulement consacrer une poésie plus haute : la flamme noire que de Cimabué à Francesca les peintres italiens ont élevée parmi les paysages toscans

\footnotetext{
${ }^{6}$ No idealiza Camus la pobreza, como en un discurso reaccionario; la comprende como una experiencia que fortalece la solidaridad. Tiene también mucho por decir sobre la injusticia social, pero no en este texto. Véase Letemendia (1997).
} 
comme la protestation lucide de l'homme jeté sur une terre dont la splendeur et la lumière lui parlent sans relâche d'un Dieu qui n'existe pas (p. 39).

Luego Camus lanza sus ojos sobre el amor evocado en los amantes del drama shakespeariano ubicado en Italia. Se ha dejado transportar a la cultura, es evidente, pero la lee como la prolongación de su propuesta nacida en la experiencia de la naturaleza con la que ha contraído estas bodas: también el amor del drama isabelino se vive en la intensidad del presente, sin esperanza de un más allá. Es entonces cuando el amor se produce en un corazón puro: uno que no niega la verdad que se le torna evidente, aunque esa verdad sea irremediablemente cruel.

Pues, como todos sabemos, el amor es trágico. Idea lacaniana: en el mejor de los casos, los amantes mueren antes de que muera el amor. Camus no lo niega, pero abre la puerta de una dicha que puede ser trágica también. La felicidad no necesariamente es optimista. Amar y saber que se ama lo que inevitablemente será de la muerte no implica una pérdida del goce amoroso, acaso solo le añade una tristeza insuperable y, de algún modo, también bella. El arte que diga esto es el que vale la pena, y no el que miente que el amor o el espíritu perduran en otro mundo. Debe saberse que los dioses son mentiras inventadas para no mirar a los ojos de la muerte, y que se han ido, nos han dejado en el desierto (así se llama, y no lo he dicho antes, este cuarto texto: "Le désert"). Pero somos capaces de procurarnos agua con una poesía que no nos mienta, solo si antes transitamos valientemente por el vacío de la desesperanza:

On sent bien qu'il s'agit ici d'entreprendre la géographie d'un certain désert. Mais ce désert singulier n'est sensible qu'à ceux capables d'y vivre sans jamais tromper leur soif. C'est alors, et alors seulement, qu'il se peuple des eaux vives du bonheur (p. 47).

Somos capaces de la vida; somos capaces de la dicha fugaz del cuerpo; somos capaces, más que todo, de mirar a la verdad de la muerte y juzgarla trágica y bella.

\section{Cántico}

Jorge Guillén elaboró este poemario por más de tres décadas. La primera edición es de 1928 y constaba de 75 poemas, que comenzaron a escribirse en 1919; la segunda (1936), de 125; la tercera (1945), de 270; la definitiva, en 1950, nos ofrece 334 poemas. Trabajaré 
con la versión última editada por Óscar Barrero Pérez en 2010. Sería imposible estudiar en detalle 334 poemas; me alegra que tampoco es necesario hacerlo para cumplir con el propósito de ahondar en el tema de la plenitud que persigue este ensayo: Guillén es un autor sumamente constante, exento de contradicciones. Cántico es un poemario al que cabe llamar "largo poema en partes". Cada parte no importa de manera separada, sino como contribución al todo. Así, pienso transitar sobre el libro con la entera libertad de quien lo sabe firmemente unido, y no se preocupa por posibles cambios súbitos de sentido. Hago constar que esto no es un prejuicio, sino la conclusión a la que llego después de leer todo el Cántico. Además, no solamente es mi opinión. Es el acuerdo unánime de la crítica consultada y detallada en la bibliografía de este ensayo. ${ }^{7}$

Con el título de "Más allá", y en diez páginas, se presenta el poema que continuó encabezando el Cántico en sus sucesivas versiones aumentadas. ${ }^{8}$ Guillén celebra la experiencia del yo lírico al despertar ante la luz de la aurora: se trata del asombro que produce el amanecer al disipar la penumbra y presentar el mundo a los ojos del poeta. Se juega con el valor de la partícula “a-” como negación: “iLuz! Me invade / Todo mi ser. ¡Asombro!” (2010, p. 30). No hay más sombra, de ahí el "a-sombro". Pero sin que mengüe el sentido normal del vocablo: admiración.

El mundo ha comenzado cuando la luz lo ilumina. El más allá al que se alude acaba en el momento mismo en que inicia el Cántico: un paréntesis significativo indica el estado previo a la luz: “(El alma vuelve al cuerpo, / Se dirige a los ojos / Y choca.)” (p. 30). Desde mi punto de vista, que acaso no comparten quienes olvidan que el más claro antecedente de este cántico es el cántico espiritual de San Juan de la Cruz, la discreción de este inicio, señalada por el paréntesis, no hace su contenido menos importante. El alma estaba separada

\footnotetext{
${ }^{7}$ Véase, por ejemplo, la observación de José María Blecua, quien a su vez se respalda en Pedro Salinas: "Guillén concibe su creación como un todo orgánico en pleno crecimiento (según la aguda observación de Salinas)..." (Gullón y Blecua, 1949, p. 150). Nótese que para ese momento toda la creación de Guillén se agrupaba en un único libro, Cántico. Para criterios más contemporáneos, véanse Díaz de Castro (1994) o Aguirre-Pérez (2012).

${ }^{8}$ Díaz de Castro (1994) da una adecuada síntesis de "Más allá": "En este extenso poema, Guillén reproduce la voz de un hombre, de su protagonista poético, que parte de la tabla rasa de un simbólico despertar del sueño y que recupera la conciencia a la vez que va reconociendo la realidad más inmediata: las sábanas, los objetos de la habitación, la luz matinal, los perfiles de las cosas en el exterior a través de la ventana. Progresivamente, el yo reconoce su pertenencia a esa realidad, la reconoce a través de los sentidos y la asume en una reflexión matinal y epifánica" (p. 5).
} 
del cuerpo durante la noche, pero de más detalles no podemos enterarnos. No sabemos lo que ocurre en ese paréntesis que apunta al más allá de nuestra experiencia, la cual no se nos manifestará abiertamente sino cuando venga la luz. Entonces será verdaderamente nuestra experiencia. El paréntesis de la luz es la noche y se encuentra más allá, y está acabándose incluso cuando nos percatamos de su existencia: el alma está regresando al cuerpo; está entrando en este por los ojos; “choca”: el verbo no puede ser más físico. ¿Quiere decir que la luz convierte al alma en materia? Más bien yo creo que se sugiere que el alma ha sido siempre materia; este podría llamarse el "cántico material", haciendo por supuesto las aclaraciones acerca de la acepción que el adjetivo tendría: apunta a la materialidad, a la afirmación del carácter físico de la experiencia humana. Guillén comienza su propio cántico en alusión al cántico de San Juan, pero separándose tajantemente. En esta línea, me atrevo a decir que Guillén pone entre paréntesis a la noche oscura del alma que San Juan ofrecía como el escenario de una explicación fundamental acerca del mundo y su origen metafísico: esa noche en que el alma va tras de Dios y lo encuentra. Guillén se abstiene de ingresar en ese terreno.

Del más allá no hay rastro. ${ }^{9}$ ¿El caos, en vez de Dios, o el caos, antes de que Dios lo tocara? El poema pregunta: “¿Hubo un caos? Muy lejos / De su origen, me brinda / Por entre hervor de luz / Frescura en chispas, ¡Día!” (p. 30). Si existió algo meramente caótico en la noche, ya se alejó tanto con la luz que no queda nada, o casi nada: el más acá es día. El mundo se presenta con claridad, de una forma gradual que avanza hasta la contundencia. Las primeras estrofas dan cuenta de un proceso que no tiene marcha atrás, hasta que al cabo la luz se impone sin ambages: "Una seguridad / Se extiende, cunde, manda. / El esplendor aploma / La insinuada mañana" (p. 31). Debe entenderse que la mañana se insinuaba en el pasado inmediato y ahora vive a plenitud, no que continúa insinuándose apenas. Por algo la siguiente estrofa dice: "Y la mañana pesa, / Vibra sobre mis ojos, / Que volverán a ver / Lo extraordinario: todo" (p. 31). Se halla aquí una contradicción lógica: si lo extraordinario es todo, entonces se convierte en ordinario. Pero no nos olvidemos de que se trata de hablar de

\footnotetext{
${ }^{9}$ Se me puede objetar que esto es extraño, dado que el poema se titula "Más allá". Pero también titula Kafka El castillo a un texto que habla sobre la imposibilidad de ingresar en un castillo. El caso es parecido, pero con una importante diferencia: Guillén no cifra la dicha en poder llegar al más allá, al contrario. Kafka, en cambio, parece bastante miserable por no entrar en el castillo. Aunque también hay matices en Kafka que no vienen al caso ahora; si son de interés, los lectores pueden consultar mi ensayo "El castillo no existe" (Víquez, 2014).
} 
una vivencia: el mundo entero se experimenta en su rotunda presentación admirable. Es, más que una propuesta racional, una descripción del asombro.

La plenitud del mundo que está se transmite sin problemas ante Guillén, de una forma tan natural como espontánea, al punto que no se ocupan explicaciones: ocurre. El yo lírico está tan pleno en el mundo como el mundo en el que está. Estar es más que ser, porque es vivir en la realidad, que no es una abstracción, sino una situación concreta. Así lo sintetiza magistralmente Guillén: “Soy, más, estoy” (p. 32).

No se intenta negar el misterio. El enigma del mundo que se presenta persiste: nadie sabe por qué está ahí; nadie sabe por qué nosotros estamos en él. Ese enigma no se puede resolver: sigue más allá. Pero esta oscuridad no tiene consecuencias perniciosas; el mundo es maravilloso de todos modos: "El balcón, los cristales. / Unos libros, la mesa. / ¿Nada más esto? Sí, / Maravillas concretas” (p. 35). Esa realidad es luminosa, aunque no lance luz sobre el misterio de su origen. Es suficiente para producir la plenitud del ser que vive en ella, ese privilegiado ser que habla y es el humano.

Pues la realidad viene al yo lírico para ser nominada por él. Así es como culmina el trayecto de la luz. Desde el enigma de su origen más allá, desconocido, hasta posarse sobre el mundo que está, pleno, y sobre el ser humano que está pleno también, al ver y estar en el mundo, bien hecho; el proceso que comenzó con la aurora no termina hasta que el yo lírico denomina las cosas que ve. Al nombrarlas, la palabra completa la plenitud de los seres que componen la realidad: "La materia apercibe / Gracia de Aparición: / Esto es cal, esto es mimbre" (p. 35). Esto consta en la IV parte de "Más allá"; una de las acepciones del vocablo "gracia” (creo es la conveniente aquí) es “nombre de pila” (DRAE, 2001, p. 1148). Cuando el yo lírico coloca sobre las cosas un nombre, cuando las bautiza, es cuando estas terminan de aparecer.

El ciclo de cada día se traza como un perfecto círculo, desde la aparición de la luz y el mundo hasta la denominación de cada cosa: no en balde "Perfección del círculo" es el título de otro poema. Resulta fundamental que el ser humano conciba la perfección del mundo y le dé nombre: será entonces el poema el que asuma el papel de lo divino que, 
hipotéticamente, está más allá, y que, de hecho, si lo está, pues allá se quedó. El acá es para la palabra.

Veámoslo más precisamente en "Perfección del círculo" (Guillén, 2010, p. 94). Los "muros de un misterio" (ese enigma que origina la realidad) se plantean como claros y amables en este poema. El enigma de la tiniebla no traspasa los límites que rodean a nuestro mundo de luz. A Guillén se le da mucho más el referirse a las cosas concretas; sin embargo, en "Perfección del círculo" aborda a un objeto que, sin dejar de ser concreto, como lo puede ser un círculo trazado en el papel, es ante todo una elaboración conceptual: la geometría nos enseña que ningún círculo es realmente el círculo que se ha dibujado, así como ningún punto es una pequeña mancha, ni ninguna línea es un grupo de angostas manchitas extendidas una tras otra. El círculo está en la mente de quien lo concibe, más aún si se subraya su perfección, lo cual resulta en cierto modo redundante: si no es perfecto no es círculo, es "semicírculo" o, peor, "seudocírculo". Pero no obsta para que sea un concepto que se manifiesta lleno de luz. El ser humano ve el círculo claramente en su cabeza: "Invisible dentro / Del bloque del aire" lo interpreto como una alusión a que en la realidad concreta del entorno no se le puede ver. "Misteriosamente / Refulge y se cela": esto lo interpreto como una alusión a que, sin que sepamos cómo, el círculo se construye para el ser humano (leo 'celar' en su acepción de 'cortar con buril o cinceles metal, piedra o madera, para darles alguna forma' [RAE, 2001, p. 492]). Se construye luminoso: sí, pero ¿quién lo hace? ¿Quién es el constructor? Hacia esas interrogantes se dirige el texto al final: “--¿Quién? ¿Dios? ¿El poema? / --Misteriosamente” (Guillén, 2010, p. 94).

Aquí hay un diálogo, tan enigmático a la hora de saber quiénes son sus participantes, como el tema mismo que se trata. Lo interpreto así: para Guillén, es imposible saber si Dios está en el origen de la perfección, pero le da una posibilidad tan grande al poema como a Dios de estar en ese origen. Dicho de otro modo, Guillén afirma que el poema participa, (¿impulsado por Dios, quién sabe?) de la perfección: la palabra hace posible que el humano toque lo perfecto. Guillén se nos demuestra, según mi lectura, como un agnóstico en cuestiones de religión, pero como un creyente en cuestiones de poesía. Porque los signos de interrogación en torno al vocablo "poema" no expresan la duda de que este exista, sino más bien la duda de que este exista de manera autónoma, sin 
un Dios más allá que crea lo perfecto, en este caso, el círculo. Esto es lo que no se puede resolver, y queda misteriosamente, pero lo que sí se resuelve es que el poema ha creado el círculo y nos ha dejado tocar su perfección luminosa, aunque de origen oscuro. El poema ha dicho; así es como interpreto esos guiones que introducen un diálogo al final de "Perfección del círculo": se trata de subrayar que ante todo hay palabras que se cruzan, incesantes palabras que están, y sin las cuales el mundo no sería perfecto. Cántico es un largo texto performativo: dice lo que hace; dice (o aspira, al menos, a decir) la perfección, lo cual la crea. ¿Como resultado de una conexión con lo divino? De esto Guillén no sabe nada. Sus afanes de poeta son de este mundo, tienen que ver con lo que es nuestro. No he mencionado, y ahora resulta oportuno hacerlo, que la reunión de toda la obra poética de Guillén consta de cinco libros (Cántico, Clamor, Homenaje, Y otros poemas, Final) y lleva por título Aire nuestro.

Me interesa destacar que Guillén celebra la plenitud como una comunión amorosa con la perfección. En lo que viene a ser un texto explicativo respecto de su propio trabajo literario, titulado significativamente El argumento de la obra, Guillén señala: "Cántico es ante todo un cántico a la esencial compañía. Quien la vive no es nunca aislado individuo (...) Este actor no sería nada fuera de su escenario" $(1969$, p. 48$) .{ }^{10}$ El texto demuestra este vínculo afectivo entre el yo lírico y su entorno (evidentemente, no estoy hablando de comunión amorosa en un sentido erótico, aunque no deja de haber poemas que sí toman ese camino: "Amor dormido", "Los labios", "Pasmo del amante" son algunas muestras). El ser humano rinde un tributo afectivo a ese mundo del que es parte, y aquí sí me resulta imposible dar solo algunas muestras: esta actitud es todo Cántico. Dondequiera que este libro se mire se encontrará el afecto profundo del yo lírico hacia el mundo perfecto, traducido muchas veces en admiración, pero sin dejar de ser afecto. Es un sentimiento en el que participa la gratitud por compartir esa delicia del existir, y el yo lírico sabe que solo puede existir porque el mundo también existe.

Poso mi atención ahora sobre lo que tiene que decirnos acerca de la plenitud "Cima de la delicia" (Guillén, 2010, p. 89). Lo haré al mismo tiempo que comento "Beato sillón”

\footnotetext{
${ }^{10}$ Otra semejanza entre Guillén y San Juan de la Cruz: ambos autores escribieron una glosa de su obra poética.
} 
(Guillén, 2010, p. 249). En el primer poema Guillén mira al aire cercano y lo identifica con el aire lejano, lo cual sintetiza en una hermosa expresión: “Todo en el aire es pájaro” (p. 89). La cima de la delicia resulta estar entonces al alcance de la mano, puesto que hay una continuidad entre el aquí y el allá, la cima (ojo: no el "más allá” del que he venido hablando; Guillén no abandona en este poema el mundo visible): "Se cierne lo inmediato / Resuelto en lejanía” (p. 89). La plenitud está en todas partes: el sol traspasa el aire que está "henchido de presencia". El poema se encuentra lleno de exclamaciones que traducen el sentimiento de gozo extremo, una plenitud de la que el mundo hace partícipe al humano que, jubiloso, declara como conclusión: “YYa solo sé cantar!” Y esto es lo que contrasta con "Beato sillón". En este último la única exclamación es la inicial, que repite el título para subrayar la felicidad de un objeto inanimado y nada raro, el habitante obligado de prácticamente todas las casas: un sillón. Con tranquilidad, el ojo (así se nombra: no se utiliza el pronombre “уo”) mira al inmediato sillón, al cercano sillón, al (casi se diría) prosaico y aburrido sillón. Y la plenitud también está allí, en esa calma, que se conoce al mirar: "Los ojos no ven, / Saben. El mundo está bien / Hecho" (p. 249). Hay incluso una alusión (me parece) a la molicie de quien reposa en el sillón: “(...) la vaga intermitencia / De su invocación en masa / A la memoria (...)” (p. 249). ¿Cabecea el ocupante de este sillón? ¿Es de la intermitencia del sueño de lo que hablamos $?^{11}$ Pero, aún así, la evidencia de la plenitud permanece. Y conste: no hay necesidad de que se produzca una demostración para ello, lo cual se expresa en esta declaración que solo por lo que implica en el contexto es muy profunda filosóficamente: "No pasa / Nada" (p. 249).

Me interesaba referirme a ambos poemas a la vez para subrayar el hecho de que en Guillén la plenitud existe universalmente. Sea en la cima del mundo o en la sala de estar, sea en la alacridad del mozo o en la pereza del que está bien sentado, sea en el vuelo del pájaro hacia el horizonte o en la quieta placidez del hogar sin novedad, el ser humano está feliz por el hecho de ser en esa realidad concreta del mundo, que en Guillén se denomina muchas veces como "estar" a secas.

\footnotetext{
${ }^{11}$ Puedo especular más, pero como ya es atrevimiento, prefiero hacerlo en una nota al pie: ¿La marea tan alta a la que alude "Beato sillón" al final, es la marea alcalina?
} 
Pero me falta referirme al tiempo y la muerte. Guillén no los pasa por alto. De hecho, en todos los poemas que llevo comentados, hay alguna alusión al tiempo, si bien la tendencia es enfatizar el presente. El glorioso presente. En el ahora el mundo está: ¿quién podría negarlo? Seguramente, no Jorge Guillén, que se aferra al hoy incluso morfológicamente: el tiempo verbal que usa con más frecuencia es el presente. No obstante, por mucho que el hoy se manifieste con la rotundidad que le da el que la realidad siempre es presente, es imposible dejar de mirar al futuro. Quiero decir que es imposible, aunque el hoy sea una experiencia dichosa, no tener conciencia de que somos finitos en el tiempo. No es un tema dominante en Cántico, pero ahí está el soneto "Muerte a lo lejos" (Guillén, 2010, p. 295) para ocuparse de él.

Este poema va más lejos que ningún otro del libro en la confesión del estremecimiento ante la muerte. El dichosísimo hoy acabará, en algún punto del futuro. No tiene caso negarlo, ni negar la angustia que esa verdad produce. Ahora bien, es interesante que, al menos en los dos cuartetos, hay atenuantes: "Alguna vez me angustia una certeza", comienza el soneto; es decir, no siempre, solo alguna vez (¿perdida?). Y luego, viendo en ese futuro la propia desaparición, se apresura a manifestar la falta de inminencia de tal: "No, no hay apuro / Todavía. Lo urgente es el maduro / Fruto. La mano ya lo descorteza." Finalmente, en los tercetos no lo logra posponer: “(...) Y un día entre los días el más triste / Será. Tenderse deberá la mano / Sin afán (...)”. Se admiten alguna angustia y tristeza entonces, pero no hay lamento ni afán de evadirse: la fatalidad se califica como justa y se la enfrenta estoicamente. El poema termina: "El muro cano / Va a imponerme su ley, no su accidente" (p. 295).

Mucho reflexioné acerca de si el Guillén del Cántico es un mero negador de la realidad de la muerte. ¿En eso se cifra su dicha, en cerrar los ojos ante la fatalidad que nos espera? Pero este soneto, con su tardanza en enfrentar a la muerte en los cuartetos y su serena aceptación de la muerte en los tercetos, me demostró algo distinto. Guillén afirma una verdad, y todo su esfuerzo lírico es para demostrar que resulta irrefutable: la ley es que la vida no dura para siempre, cierto, pero no es menos cierto que la ley es que la vida solo ocurre en el presente. Cuando la muerte se dé, implacable, ya no será un acontecimiento que afecte la vida: la termina, pero no la modifica, puesto que no se puede modificar lo que 
ya no existe. En el fondo, resuena Epicuro: “(...) el ser, una vez disuelto, es insensible, y la condición insensible no tiene nada que ver con nosotros" (2014, p. 93). Así que el Cántico es una celebración de que la vida es plena y es hoy, y el hecho de que se acabe no cambia el hecho de que lo sea.

Hay una última pregunta que podría surgir. ¿Espera Guillén alguna suerte de trascendencia humana después de la muerte? Creo que aquí también impera el Guillén agnóstico, que no da mayores muestras de estar enterado al respecto. Poemas como "Navidad" o "Sábado de Gloria" los interpreto no como las profesiones de fe que aparentan, sino como celebraciones de una religiosidad que se parece a la confianza en el presente tan cara a Guillén. Es que la fiesta religiosa también es un gozo del hoy: nótese que estos poemas se dedican a fechas del calendario de festividades católicas. Sé que esto es discutible (hay versos como "El Señor resucitó” [Guillén, 2010, p. 137] o “¡Tú nos salvas, / Criatura / Soberana!” [p. 215]), pero, aunque Guillén le concediera la existencia a un dios, me parece que no se compromete mayormente con la afirmación de que esa divinidad permita a los seres humanos el sobrevivir a la muerte. La alegría de Guillén está cifrada en el hoy de quien aún está vivo. Después, al igual que antes, nadie los sabe, y Guillén no los afirma. Quizás porque en el fondo le parecen innecesarios: el presente es suficiente para vivir en dicha rebosante.

\section{La comparación y las conclusiones}

Camus y Guillén comparten en estos textos la actitud de celebración de la vida como experiencia actual. El ser humano está vivo hoy, y esto es lo medular. No es simplista porque sea evidente, porque muchas veces olvidamos lo evidente. Nos distraemos de ello, así como nos distraemos del mundo concreto en el que se desarrolla nuestra vida. Camus y Guillén proclaman que debe uno mirar lo que está en sus narices: que está vivo y que el presente en el mundo concreto es todo lo que realmente existe.

El mundo lo constituye solo lo que alcanza a nuestros sentidos. Para ambos autores, ayunos de metafísica, esto es un hecho. Ayunos a propósito de metafísica; no se trata de un olvido, sino de una decisión filosófica. Pero Camus encuentra la dicha personal en la 
inmersión sensual en ese mundo material, y más propiamente en la naturaleza. No es que no quiera gozar de la cultura; es que el cuerpo (y se trata del cuerpo, no del alma) encuentra el placer en los elementos naturales antes que en los culturales. Pero no se detiene allí: es capaz de gozar del arte y de encontrar la belleza en él, como un placer también. Se trata de un énfasis, con todo: primero es capaz de ser feliz en el mar, bajo el sol, embriagado de perfumes, y luego mirará la pintura de los maestros italianos. Tal tendencia no se manifiesta de igual manera en Guillén. Su celebración del mundo material, aunque centrada en la luz y el aire (elementos naturales, obviamente), no enfatiza en los placeres de los sentidos, salvo en uno: el de la vista. Camus celebra con todo el cuerpo, mientras Guillén sobre todo mira para celebrar. Esa mirada de Guillén no le da especial importancia a la luz y el aire porque sean elementos naturales, sino porque son los que permiten que el mundo se manifieste a la vista. Son lo que hace al ser humano ver que está en el mundo, y luego todo ese mundo tiene igual importancia para Guillén. No más el mar que un sillón. No más un perfume silvestre que una mesa. Para Guillén, sería impropio darle mayor categoría existencial al sol que a un bombillo. Para Camus, no.

Guillén no niega tan tajantemente como Camus la existencia del alma que habita en el cuerpo. La materializa, eso sí, y en mucho esto la hace perder su diferencia específica en relación con el cuerpo. No parece ser un problema que le preocupe, porque al fin y al cabo es un poeta que puede jugar con el sentido del vocablo para evocar la experiencia humana más sublime. Camus, más ducho en la filosofía, no se permite tal cosa. Otro tanto acontece con la Divinidad. Camus la niega explícitamente, mientras Guillén se concede cierta ambigüedad al respecto. En este ensayo, yo he querido sostener la visión de un Guillén agnóstico, un Guillén que por su apego mil veces declarado al mundo presente no intenta darse explicaciones teológicas de ese mundo. En cuanto a Camus, su ateísmo es manifiesto y una parte integral de su capacidad para el goce: solo sin dioses logramos vivir el hoy plenamente.

En todo caso, lo que sí está claro es que ambos sostienen que el ser humano es capaz de ser feliz, cuando se entrega al mundo concreto y presente. La realidad se encarga de darnos todo lo que necesitamos para ser dichosos, si entendemos que debemos verla como una ocasión rotunda para estar. Estar en el sentido guilleneano es más que ser, porque 
implica ser sabiéndose y sintiéndose ser en el mundo. La realidad solo puede celebrarse por una razón que aparenta sencillez, pero solo la aparenta, porque conlleva el enigma: su concretísima aparición. Ya que el mundo está, y yo estoy, eso implica que tengo la dicha de estar. Sumergido en los goces del cuerpo (Camus) o jubiloso o plácido en la visión admirable del mundo (Guillén), vivo la dicha de que todo existe. La puerta de la plenitud está abierta para quienes sepan que la plenitud nos está invitando a participar de ella. Hoy. Aquí. Basta querer entrar a un sitio en donde de por sí ya estamos: la cuestión es no distraernos.

Evidentemente, lo que más puede distraernos de tal dicha es la perspectiva de la muerte. Guillén y Camus ofrecen soluciones distintas, aunque ya dice mucho de su afinidad el que al fin y al cabo consigan ofrecer soluciones ante tamaña amenaza. Guillén ha mirado mucho más que Camus hacia el origen. Se ha preguntado de dónde viene todo lo que experimenta con gozo. Se ha dejado intrigar por el misterio del nacimiento de la luz, para ponerlo en términos que no le son ajenos. Y ha renunciado a explicarlo. No le hace falta: su gozo no es menor por no estar explicada su procedencia. Entonces, del mismo modo, renuncia Guillén a permitir que su gozo sea menor porque lo sabe pasajero. Cuando la vida acaba, no hay tristeza: tendrías que estar vivo para estar triste. Mientras hay vida, hay gozo. La muerte no se niega, lo que se niega es que pueda ser real para un ser que está vivo, es decir (suena a perogrullada, disculpen), no muerto. Es Epicuro. En cuanto a Camus, su cuestionamiento por el origen de todo es mucho menor; pero su decepción ante la perspectiva de la muerte, mucho mayor. Ya he citado que se refiere a la muerte como una "sucia aventura", lo cual suena bastante peor que la expresión de Guillén, quien la llama “justa fatalidad”. No obstante, Camus logra mirar hacia la tragedia humana como un posible escenario para la belleza. La plenitud del nadador al sol, que experimenta el placer al tiempo que lo agota, no se extenderá para siempre, pero al menos somos capaces de mirar hacia ese triste final con hermosura en los ojos.

El Camus de Noces resuelve pues, el problema de la muerte, con el arte, al que aquí mira en los maestros pintores toscanos, llamados por él "novelistas del cuerpo". Es escritor y no puede evitar concebir el arte en términos verbales. La poesía (no la pensemos exclusivamente ligada a un género literario) toma las riendas del rescate: no nos salva de la 
muerte, pero nos ofrece la belleza para mirar hacia esa "sucia aventura". Cuando llegue, eso será, "sucia aventura", pero mientras no llegue, puede ser poesía. Guillén, por su parte, va más allá en su reflexión en torno a la palabra. En él, esta cumple el importante papel de completar el círculo perfecto de la existencia de las cosas en el mundo humano. La realidad culmina porque se dice; la realidad se completa en su nominación. Guillén no sostiene que necesariamente el ser humano cumple el papel de la divinidad, porque abre la puerta para que sea Dios el origen primero de todo, incluso de la palabra humana. Pero, como no está seguro de ello, no deja de exaltar aquello que efectivamente pasa: el poema dice la realidad y así el ser humano puede elevarse hasta la perfección de esa realidad.

Al fin, entre poetas estamos. Poetas de la rara especie que -en lugar de agobiarnos con los lamentos usuales- nos proponen la poesía como el fundamento para una felicidad posible. Me alegro de haberlos escuchado.

\section{Referencias bibliográficas}

Aguirre-Pérez, F. (2012). El destierro de la historia: la poética del universo auroral y perfecto en Cántico de Jorge Guillén. Hispanofila, 16(5), 51-65.

Camus, A. (1959). Noces, suivi de L'été. Paris: Gallimard.

Díaz de Castro, F. J. (1994). Jorge Guillén: un poeta de la afirmación. España: Universitat de les Illes Balears.

Epicuro. (2014). Obras completas. Madrid: Cátedra.

Guillén, J. (1969). El argumento de la obra. Barcelona: Llibres de Sinera.

Guillén, J. (2010). Aire Nuestro. Cántico. Clamor (Tomo 1). Barcelona: Tusquets.

Gullón, R. y Blecua, J. M. (1949). La poesía de Jorge Guillén. Zaragoza: Heraldo de Aragón.

Letemendia, V. C. (1997). Poverty in the Writings of Albert Camus. Polity, 29(3), 441-460. Recuperado de http://www.jstor.org/stable/3235315 
Massé, O. (2015). L’influence décisive de Nietzsche sur le jeune Camus. Phares, XV(08), 147-165.

Montgomery, G. F. (2006). Reseña de 'Sensing', 'Seeing', 'Saying' in Camus's Noces: A Meditative Essay, by James W. Brown. The French Review, 79(4), 844-845.

Onfray, M. (2012). L'ordre libertaire. La vie philosophique d'Albert Camus. Paris: Éditions J'ai lu.

Real Academica Española (RAE). (2001). Diccionario de la Lengua Española (DRAE). Madrid: Autor.

Tall, E. (1980). Soviet Responses to Albert Camus, 1956-1976. Canadian Slavonic Papers / Revue Canadienne des Slavistes, 22(3, September), 319-337.

Viggiani, C. A. (1960). Albert Camus' First Publications. Modern Language Notes, 75(7), 589-596. Recuperado de http://www.jstor.org/stable/3040226

Víquez, A. (2014). El castillo no existe. Káñina, Revista de Artes y Letras, XXXVIII(1), 7794.

\section{Literatura consultada}

Calvo Carilla, J.L. (1993). La definitiva plenitud del mundo guilleniano: el "Cántico" de 1936. Anales de la literatura española contemporánea, 18(1/2), 309-322.

Debicki, A. (1966). Jorge Guillén's Cántico. PMLA, 81(5), 439-445.

Faulkner, W. (1961). Albert Camus. The Transatlantic Review, 6, 5. Recuperado de http://www.jstor.org/stable/41511922

Hanna, T. L. (1956). Albert Camus and the Christian Faith. The Journal of Religion, 36(4), 224-233.

Joyaux, G.T. (1960). Albert Camus and North Africa. The French Studies, 25, 10-19.

LeBlanc, J.R. (1999). Art and Politics in Albert Camus: Beauty as Defiance and Art as a Spiritual Quest. Literature \& Theology, 13(2), 126-148. 
Nguyen-Van-Huy, P. (1962). La métaphysique du bonheur chez Albert Camus. Suisse: Editions La Baconnière.

Olmos, M.A. (2008). Jorge Guillén y la crítica de la oscuridad. Simbolismo e interpretación en Lenguaje y poesía. Dicenda. Cuadernos de FilologíaHispánica, 26, 169-192.

Olson, J.C. (1969). Le dualisme chez Albert Camus: le bonheur et l'absurde (tesis de maestría). The University of British Columbia, Canadá.

Pozuelo Yvancos, J.M. (2006). La poética y la crítica literaria de Jorge Guillén. España: Editorial del Cardo.

Robles Ávila, S. (2001). Jorge Guillén en su realidad esencial: Indagaciones semánticas sobre Cántico (tesis doctoral). Universidad de Málaga, España.

Vega, M.J. y Carbonell, N. (1998). La literatura comparada: principios y métodos. Madrid: Gredos.

Vargas Llosa, M. (1976). Camus y la moral de los límites. INTI, Revista de literatura hispánica, 4(otoño), 7-21. 